\title{
AMBIDEKSTERITAS ORGANISASIONAL: ISU RISET DAN ANTESEDEN
}

\author{
Vitradesie Noekent \\ Fakultas Ekonomi \\ Email : vitradesienoekent@gmail.com \\ Universitas Negeri Semarang \\ Gedung C6 Kampus Unnes Sekaran, Gunungpati, Semarang. 57144.
}

\begin{abstract}
There are two main issues in organizational ambidexterity. Firstly, structure-based organizational ambidexterity argued that the tension between exploration and exploitation can reconcile by creating the separated organizational structure for different activity. Secondly, contextual-based organizational ambidexterity stressed the influence of organizational context to create behavior for balancing exploration and exploitation activities. This article argue that he structural dimension and organizational behavior will produce micro foundation which is the interaction between both dimension will produce exploration and exploitation processes as organizational outcome.
\end{abstract}

Keywords: organizational ambidexterity, exploration, exploitation, micro foundation.

\begin{abstract}
Abstrak: Terdapat dua isu dalam riset ambideksteritas organisasional. Pertama, ambideksteritas organisasional berdasar struktur yang berargumen bahwa tensi eksplorasi dan eksploitasi dapat direkonsiliasikan dengan cara menciptakan struktur organisasi yang terpisah bagi aktivitas eksplorasi. Kedua, ambideksteritas organisasional berdasar konteks menekankan perlunya konteks organisasi untuk membentuk perilaku bagi berlangsungnya aktivitas eksplorasi dan eksploitasi secara seimbang. Riset ini berargumen bahwa dimensi struktur dan perilaku organisasional akan menciptakan fondasi mikro dimana interaksi keduanya akan menghasilkan outcome organisasional berupa proses eksploitatif dan eksploratif (Simsek, 2009).
\end{abstract}

Kata kunci: ambideksteritas organisasional, eksplorasi, eksploitasi, fondasi mikro.

\section{PENDAHULUAN}

Organisasi telah beradaptasi dalam menghadapi perubahan dan ketidakpastian lingkungannya dari waktu ke waktu, sebagai contoh: IBM telah merubah strategi dari produsen hardware menjadi penyedia software (Tushman, O'Reilly, \& Harreld, 2013) dan Hewlett Packard (HP) berubah dari pembuat instrumen elektronik menjadi mini komputer hingga printer walau gagal ketika bertransisi ke industri jasa (House \& Price, 2009). Upaya mereka untuk beradaptasi kemudian menjadi sukses atau mengalami kegagalan telah menjadi dasar pemikiran cendikia di berbagai bidang, antara lain: manajemen, sejarah, strategi, sosiologi organisasi, psikologi dan ilmu ekonomi (e.g., Christensen, 1997; Hannan \& Freeman, 1984; Nelson \& Winter, 1982; Staw, Sandelands, \& Dutton, 1981; Tushman et al., 1985).
Berdasar pemikiran tersebut, telah dihasilkan teori-teori organisasi seperti: keunggulan kompetitif (Porter, 1980), konflik strategik (Shapiro, 1989), ekologi organisasional (Hannan \& Carroll, 1992), punctuated evolution (Tushman \& Romanelli, 1985), teori institusional (Meyer \& Rowan, 1977), threat-rigidity (Staw et.al. 1981), perspektif sumber daya organisasi (Barney, 1991) dan kapabilitas dinamis (e.g., Eisenhardt \& Martin, 2000; Teece, Pisano, \& Shuen, 1997). Teori-teori tersebut di atas pada dasarnya berupaya mengungkap fenomena dibalik proses adaptasi dan perubahan organisasi hingga memunculkan pertanyaan mendasar: Dapatkah organisasi beradaptasi dan kemudian berubah? Jika dapat beradaptasi, bagaimana hal tersebut terjelaskan ? Pertanyaan-pertanyaan ini kemudian menjadi perdebatan dua kubu, yaitu: para cendikia yang berargumen bahwa 
perubahan terjadi karena proses adaptasi (e.g., punctuated evolution theory, teori kapabilitas dinamis), dan para cendikia yang berargumen bahwa perubahan terjadi melalui proses evolusioner mikro: variasi- seleksi- retensi.

Terdapat cukup data empiris untuk mendukung kedua argumen. Louca dan Mendoca (2002) dalam studinya terhadap 200 perusahaan manufaktur terbesar di US menyatakan bahwa perubahan dan instabilitas adalah sebuah fitur pemanen yang intensitasnya meningkat dari waktu ke waktu, hanya 28 (atau 5\%) dari 267 perusahaan yang dapat bertahan di akhir abad ke-20. Bahkan sebanyak 49\% dari mereka hanya muncul sekali dan kemudian menghilang, menguatkan dugaan bahwa mereka tidak dapat beradaptasi dan selanjutnya tergantikan. Stubbart \& Knight (2006) dalam survai firms' life span menguatkan fenomena tersebut dengan menginvestigasi terjadinya disappearing firms- yaitu perusahaan-perusahaan yang hilang karena proses merger, akuisisi atau divesment- dan menemukan bukti bahwa perusahaan yang sukses sekalipun hanya dapat bertahan dalam waktu yang singkat setelah mengalami perubahan identitas secara mendasar berupa perubahan nama, merk, aset atau sistem operasi.

Lebih lanjut, meski telah diakui sebagai kontributor namun kedua kubu perdebatan di atas (adaptasi vs evolusioner) belum menghasilkan kesimpulan yang konklusif mengenai kondisi apa yang membuat beberapa organisasi mampu mempertahankan keunggulan kompetitif menghadapi transisi lingkungannya, sementara yang lain tidak (O'Reilly \& Tushman, 2008). Salah satu literatur yang berupaya menjawab debat ini dan memperoleh atensi luar biasa dari para cendikia adalah literatur ambideksteritas organisasional. Ide dasar ambideksteritas adalah kesuksesan organisasi sangat ditentukan oleh kemampuan mereka mengelola tradeoff (Gibson \& Birkinshaw, 2004). Literatur pembelajaran organisasi yang menjadi pangkal ide ambideksteritas menyebutkan agar dapat bertahan dan sejahtera maka organisasi akan selalu bergantung pada seberapa baik mereka melakukan pembelajaran dalam organisasi, yaitu bagaimana mereka harus memperoleh dan kemudian mengintegrasikan pengetahuan secara kontinyu (Kang \& Snell, 2009).
Menurut March (1991), ambideksteritas merupakan kemampuan organisasi untuk melakukan dua moda pembelajaran secara simultan dimana keduanya menimbulkan trade-off. Pada banyak riset pembelajaran organisasi, trade-off ini fokus pada dua jenis moda belajar yaitu eksplorasi dan eksplotasi. Aktivitas eksplorasi merupakan pencarian hal-hal yang baru dan melibatkan proses penemuan dan eksperimen, menyerap atau menciptakan konsep atau teknologi baru, dan mengembangkan kemampuan baru yang mungkin diluar bidang keahlian saat ini. Sementara aktivitas eksploitasi merupakan tindakan menggunakan dan mengembangkan hal-hal yang telah diketahui yang dicapai melalui pengumpulan pengalaman dari sejumlah keahlian dan meningkatkan kemampuan tersebut melalui latihan berulangulang dan formalisasi pengetahuan (Levinthal \& March, 1993).

Cendikia lainnya juga menegaskan terjadinya trade-off, seperti: efisiensi dan fleksibilitas dalam proses manufaktur (Adler, Goldoftas, \& Levine, 1999), strategi diferensiasi dan strategi biaya rendah (Porter, 1980, 1996), strategi integrasi global dan respon lokal (Bartlett \& Ghosal, 1989). Literatur ambideksteritas organisasional menekankan agar bertahan dan sukses menghadapi tantangan, organisasi harus unggul dalam melakukan inovasi yang bersifat eksploitatif maupun eksploratif (Tushman \& O'Reilly, 1996). Organisasi dituntut untuk mengelola trade-off yang timbul akibat perbedaan dalam proses menghasilkan pengetahuan dari kedua jenis aktivitas tersebut (March, 1991). Bahwasanya, inovasi adalah proksi keberhasilan organisasi dalam mengelola trade-off yang dapat berupa: tensi (Lewis et.al, 2002), paradoks (Miron et al., 2004), kontradiksi (King, Anderson, \& West, 1991), dilema (Benner \& Tushman, 2003), atau apa yang disebut sebagai dark side of innovation processes (Anderson \& Gasteiger, 2007). Pendek kata, fakta bahwa trade-off telah dianalisis secara luas pada berbagai level dan berbagai jenis organisasi sebagaimana diuraikan pada Tabel 1 menunjukkan bukti bahwa organisasi berupaya untuk melakukan inovasi dengan segala hambatannya untuk mencapai keunggulan kompetitif dalam jangka panjang. 
Tabel 1. Trade-off yang terjadi pada proses inovasi di berbagai level analisis

\begin{tabular}{|c|c|c|}
\hline Level individu & Level tim & Level organisasi \\
\hline $\begin{array}{l}\text { - Openness to Experience } \\
\text { dan Conscientiousness pada } \\
\text { perusahaan manufaktur (George \& } \\
\text { Zhou, 2001) } \\
\text { - Artistic/investigative dan } \\
\text { conventional interests (Holland \& } \\
\text { Gottfredson, 1992) } \\
\text { - Cara berpikir konvergen dan } \\
\text { divergen (Guilford, 1967) } \\
\text { - Adaptor dan inovator (Kirton, } \\
\text { 1976) } \\
\text { Mood Positif dan negatif (George } \\
\text { \& Zhou, 2007) } \\
\text { Fokus promosi dan pencegahan } \\
\text { (Forster, Higgins, \& Taylor- } \\
\text { Bianco, 2003) } \\
\text { Orientasi pada tujuan } \\
\text { pembelajaran dan kinerja (Yeo \& } \\
\text { Neal, 2004) } \\
\text { Penghargaan eksternal dan } \\
\text { motivasi intrinsik (Collins \& } \\
\text { Amabile, 1999) } \\
\text { Riset akademik dan komersialisasi } \\
\text { pada perguruan tinggi (Ambos } \\
\text { et.al., 2008) }\end{array}$ & $\begin{array}{l}\text { - } \mathrm{K} \text { e } \mathrm{p} \text { e m i m p i } \mathrm{n} \text { a } \mathrm{n} \\
\text { transformasional dan } \\
\text { inisiasi struktur pada unit } \\
\text { R\&D (Keller, 2006) } \\
\text { Kreativitas dan standarisasi } \\
\text { pada perusahaan } \\
\text { multinasional (Gilson, } \\
\text { et.al, 2005) tim (e.g., } \\
\text { Diversitas tim } \\
\text { Hulsheger, Anderson, \& } \\
\text { Salgado, 2008) } \\
\text { Divergent team processes, } \\
\text { misal: minority dissent (De } \\
\text { Dreu, 2002) } \\
\text { Convergent team } \\
\text { processes, misal: } \text { shared } \\
\text { vision (Hulsheger } \text { et al., } \\
\text { 2008) }\end{array}$ & $\begin{array}{l}\text { - Nilai-nilai kultural dan } \\
\text { praktik bagi inovasi, } \\
\text { efisiensi dan kualitas pada } \\
\text { perusahaan R\&D (Miron, } \\
\text { Erez, \& Naveh, 2004) } \\
\text { - Otonomi dan kontrol } \\
\text { (Gebert, Boerner, \& } \\
\text { Lanwehr, 2003) } \\
\text { - Rutinitas organisasional } \\
\text { dan kapabilitas dinamik } \\
\text { (Zahra \& George, 2002) } \\
\text { Kompetensi inti dan core } \\
\text { rigidities (Leonard-Barton, } \\
\text { 1992) } \\
\text { Prospektor dan reaktor } \\
\text { (Miles \& Snow, 1978) } \\
\text { Momentum berbasis inersia } \\
\text { dan perubahan (Jansen, } \\
\text { 2004) }\end{array}$ \\
\hline
\end{tabular}

Sumber: Bledow et.al. (2009); Ambos et.al., (2008)

Sayangnya, mayoritas riset $\mathrm{di}$ atas dilakukan pada perusahaan manufaktur dengan unit $R \& D$ untuk produk berteknologi tinggi pada pasar di negara maju, sehingga masih terbuka ruang riset bagi jenis industri lainnya, antara lain industri jasa seperti perguruan tinggi yang berada di negara sedang berkembang. Selain itu, Raisch dan Birkinshaw (2009) dan Mom et al. (2009) menyatakan bahwa riset ambideksteritas baik secara konseptual maupun empirikal - dominan dilakukan pada level unit bisnis atau perusahaan, namun kurang memberi perhatian pada pencapaian ambideksteritas level individu. Demikian pula dengan riset yang menganalisis variasi ambideksteritas antar manager (Gupta et al., 2006; Raisch \& Birkinshaw, 2008). O'Reilly dan Tushman (2004) menegaskan pentignya analisis pada level individu dengan menyatakan bahwa perusahaan ambidektrus membutuhkan tim senior dan manager yang ambidektrus pula.

Artikel ini bertujuan untuk memperoleh pemahaman mendalam tentang bagaimana ambideksteritas pada level individu memampukanterciptanyaambideksteritaspada level organisasi dengan cara mengeksplorasi elemen struktur berupa organizational capital dan elemen perilaku berupa social capital, dan human capital menggunakan kerangka Kang dan Snell (2009).

\section{RERANGKA TEORITIS}

Keputusanindividuuntukmengalokasikan waktu dan sumberdaya organisasi yang menjadi kewenangannya menjadi hal yang menarik untuk dianalisis baik secara teoritikal maupun praktikal. Hal ini disebabkan pengembalian yang berasal dari aktivitas eksplorasi bersifat kurang pasti, memiliki resiko kegagalan yang tinggi, dan membutuhkan waktu yang lebih lama jika dibandingkan dengan aktivitas eksploitasi. Karenanya, individu cenderung memprioritaskan aktivitas eksploitasi dibanding eksplorasi (March 1991).

Ketidakseimbangan aktivitas eksplorasi dan eksploitasi dapat mengakibatkan dampak negatif pada keberlangsungan organisasi. Fokus pada aktivitas eksploitasi hanya mendorong kinerja jangka pendek, dan dapat mengakibatkan terjadinya jebakan kompetensi karena perusahaan tidak memiliki kekuatan cukup untuk merespon perubahan lingkungan, seperti perubahan pasar atau tehnologi. Sebaliknya, penekanan pada aktivitas eksplorasi saja, mungkin akan mendorong 
kemampuan perusahaan untuk senantiasa memperbarui basis pengetahuannya, tetapi di sisi lainnya dapat pula menjebak perusahaan pada siklus pencarian yang tiada henti yang menimbulkan perubahan tanpa hasil yang memadai (Volberda \& Lewin, 2003). Eksplorasi dan eksploitasi juga bersaing dalam menggunakan sumber daya, sehingga batas optimal keduanya menjadi kunci keberhasilan kinerja organisasi.

Kesadaran dan kebutuhan akan pentingnya melakukan eksplorasi dan eksploitasi serta menjaga keseimbangan diantara keduanya menjadi dasar terbentuknya strategi ambideksteritas (Benner \& Tushman, 2003; March, 1991). Strategi ambideksteritas mengacu pada sinkronisasi kegiatan eksplorasi dan eksploitasi melalui penggabungan atau pemisahan sub unit atau individu, yang masingmasing mengkhususkan diri baik dalam eksplorasi atau eksploitasi dan melakukan keduanya secara simultan (Gupta et.al., 2006). Organisasi yang memiliki sifat ambidekstrus dapat unggul dan sejahtera karena mereka mampu mengenali kesempatan, keterkaitan dan sinergi antara aktivitas eksplorasi dan eksploitasi (Smith \& Tushman, 2005).

Duncan (1976) adalah cendikia pertama yang menginisiasi istilah organisasi ambidekstrus untuk menggambarkan struktur ganda dari banyak perusahaan dalam mengelola dua aktivitas kontradiktif yang berbeda dalam hal waktu dan kemampuan managerial untuk menghasilkan inovasi. Dua puluh tahun kemudian, Tushman dan O'Reilly (1996) menggunakan konsep tersebut untuk menjelaskan bagaimana perusahaan dapat mengelola proses perubahan yang bersifat evolusioner dan revolusioner. Persamaan pendapat kedua cendikia ini adalah penekanannya pada pemisahan struktur organisasi untuk aktivitas yang menimbulkan tensi, dan inilah yang disebut sebagai ambideksteritas struktural. Di sisi lain Gupta dan Birkinshaw (2004) menyatakan perbedaan pendapatnya. Bahwasanya, trade-off akan dapat dikelola dengan baik jika organisasi menciptakan konteks yang memampukan individu di dalamnya untuk menjalankan peran eksplorasi dan eksploitasi secara simultan, dan inilah yang disebut sebagai ambideksteritas kontekstual.
Ambideksteritas organisasional - baik yang dicapai melalui struktural maupun kontekstual - adalah fenomena multilevel (Raisch \& Birkinshaw, 2008). Untuk itu, mereka menegaskan dibutuhkannya studi yang mencakup beberapa level analisis. Kurangnya riset yang menganalisis ambideksteritas secara multi-level dan multi-domain akan membatasi pemahaman kita tentang sebuah konsep dan hal ini menunjukkan pula kelemahan sebuah teori (Gupta et.al., 2006; Raisch \& Birkinshaw, 2008). Fenomena multi-level dan multi-domain sebagai sebuha sistem dalam organisasi dapat dianalisis dari proses terbentuknya sebuah unit kerja menjadi ambidekstrus, yaitu dengan cara membentuk fungsi atau sub-divisi dengan fokus yang berbeda bagi keduanya (e.g., Adler, Goldoftas, \& Levine, 1999; Benner \& Tusman, 2003) atau dengan cara memberi peran yang berbeda pada tiap individu dalam organisasi (e.g., Jansen et.al., 2008).

Lebih lanjut, Birkinshaw dan Gupta (2013) merujuk pada pemikiran Simon (1962) tentang organisasi, menguatkan pendapat ini dengan menyatakan bahwa organisasi adalah sebuah sistem yang hampir terdekomposisi, dimana setiap bagiannya harus membangun hubungan dengan bagian lainnya, yang artinya sebuah organisasi yang dikelola dengan efektif akan memiliki perpaduan aktivitas eksplorasi - berupa pencarian hal-hal yang baru dan melibatkan proses penemuan dan eksperimen, menyerap atau menciptakan konsep atau teknologi baru, dan mengembangkan kemampuan baru yang mungkin di luar bidang keahlian saat ini - dan sekaligus aktivitas eksplotasi - tindakan menggunakan dan mengembangkan hal-hal yang telah diketahui yang dicapai melalui pengumpulan pengalaman dari sejumlah keahlian dan meningkatkan kemampuan tersebut melalui latihan berulang-ulang dan formalisasi pengetahuan di setiap unitnya (Levinthal \& March, 1993). Berdasar perbedaan tersebut, peneliti harus dapat mengidentifikasi dengan tepat pada level apa trade-off eksplorasi dan eksploitasi terjadi dan pada level apa diselesaikan (Raisch \& Birkinshaw, 2008). Sesuai dengan tujuan kedua, maka riset ini akan fokus pada upaya mengeksplorasi mekanisme dalam organisasi berupa fondasi mikro yang disain untuk mengelola trade-off 
yang terjadi pada level individu sebagaimana digali oleh pertanyaan pertama riset ini.

Beberapa bukti empiris menunjukkan manfaat eksplorasi dan eksploitasi

1) mempengaruhi kesuksesan dan keberlangsungan organisasi dalam jangka panjang (Gibson \& Birkshaw, 2004); 2) menghasilkan keuntungan dalam inovasi produk dibanding kompetitornya yang hanya berfokus pada satu aktivitas (Katila \& Ahuja, 2002); 3) memampukan organisasi untuk mencapai keunggulan kompetitif, seperti: pertumbuhan penjualan (Auh \& Menguc, 2005; Han \& Celly, 2008; He \& Wong, 2004), inovasi (Adler, Goldoftas, \& Levine, 1999; Burgers et.al., 2009; Yang \& Atuahene-Gima, 2007); dan 4) melakukan penilaian kinerja secara subjektif (Bierly \& Daly, 2007; Cao, Gedajlovic, \& Zhang, 2009). Sayangnya, riset ambideksteritas lebih banyak dilakukan di negara maju yang juga didominasi oleh konteks perusahaan berukuran besar dan berusia panjang.

Sejauh pendalaman literatur, riset ambideksteritas organisasional dengan konteks perguruan tinggi masih minim dilakukan. Perkecualian dilakukan oleh Ambos et.al. (2008) yang mengaplikasikan literatur ambideksteritas organisasional pada perguruan tinggi di UK. Sebagaimana korporasi, perguruan tinggi juga dihadapkan pada trade-off berupa riset akademik dan komersialisasi. Hasil studi Ambos et.al. (2008) menunjukkan bahwa pada level organisasi, trade-off ini dapat diselesaikan dengan pembentukan struktur ganda, sedang pada level individu trade-off ini menjadi lebih akut. Riset ini berupaya memperdalam riset Ambos et.al. (2008) menggunakan objek riset perguruan tinggi di Indonesia sebagai negara berkembang.

\section{ISU-ISU RISET}

Lebih lanjut, sebagai paradigma riset yang terus berkembang, literatur ambideksteritas organisasional memiliki beberapa isu riset. Isu pertama dalam hal theoretical gap yang diklasifikasikan menjadi tiga pendapat, yaitu: 1) Gupta, Smith, dan Shalley (2006) yang menyatakan bahwa ambiguitas definisi dan implikasi eksplorasi dan Eksplotasi terjadi karena perbedaan pada pandangan mengenai: jenis pembelajarannya (Baum, Li, \& Usher, 2000; Benner \& Tushman, 2002; He \& Wong, 2004), terjadi atau tidaknya proses pembelajaran (e.g., Rosenkopf \& Nerkar, 2001; Vasosolo, Anand, \& Folta, 2004; Vermeulen \& Barkema, 2001); 2) Nosella, Cantarello, \& Filippi (2012) dalam studi bibliografinya menyatakan bahwa tinggi minatnya terhadap topik ini telah turut mengaburkan kejelasan definisi ambideksteritas organisasional dan dengan demikian mengurangi potensinya sebagai kapabilitas yang memampukan organisasi untuk menyelesaikan tensi antara eksplorasi dan eksploitasi; 3) Birkshaw dalam Birkshaw dan Gupta (2013) menyatakan intepretasinya bahwa saat ini (2009-2013), riset-riset mengenai ambideksteritas organisasional telah sampai pada tahap konsolidasi dimana sejumlah riset telah mengeksplorasi aspek tambahan ambideksteritas dan berhasil menunjukkan konvergensi hasil penelitian pada temuan eksplorasi-eksploitasi.

Isu kedua dalam hal empirical gap. Berdasar kumpulan riset empiris, sedikit dari riset tersebut yang bertujuan mengidentifikasi sistem dalam organisasi yang dapat memfasilitasi ambideksteritas kontekstual (Lavie et.al., 2010; Simsek, 2005; Simsek et.al., 2009). Ditambahkan pula oleh Gibson dan Birkinshaw (2004) bahwa sistem dan proses dalam organisasi yang dibentuk secara cermat akan memampukan organisasi untuk mempertahankan kinerja jangka panjangnya. Micro foundations apa yang dibutuhkan untuk mendukung implementasi kapabilitas dinamis yang harus lebih dieksplorasi oleh peneliti mendatang. Lebih lanjut, Simsek (2009) menyatakan bahwa riset ambideksteritas saat ini nampaknya hanya melibatkan satu lensa untuk menjelaskan sebuah fenomena, seperti struktur ganda pada kasus ambideksteritas struktural (Benner \& Tushman, 2003), konteks organisasi pada ambideksteritas kontekstual (Gibson \& Birkinshaw, 2004) atau integrasi perilaku para pimpinan puncak (Lubatkin et.al., 2006). Berdasar permasalahan ini, akan sangatlah bermanfaat bagi studi mendatang untuk menganalisis hubungan antara ambideksteritas kontekstual dan struktural.

Selain itu, Junni et.al. (2013) juga menyatakan bahwa hubungan antara ambideksteritas organisasional dan kinerja 
dimoderasi oleh faktor-faktor kontekstual dan pilihan metodologi yang spesifik. Konsep ambideksteritas organisasional lebih berpengaruh pada industri non manufaktur dan pada level analisis yang lebih tinggi (unit bisnis atau perusahaan). Pengaruhnya pada kinerja akan lebih kuat manakala menggunakan kombinasi pengukuran ambideksteritas organisasional dengan kinerja perseptual. Dari sisi metode, penggunaan data cross-section atau disain riset multi-method menjadi lebih tepat untuk menganalisis fenomena ambideksteritas yang bersifat multilevel (Birkinshaw \& Gupta, 2013).

Isu ketiga dalam hal practical gap. Pada kenyataannya, penelitian ambideksteritas lebih banyak dilakukan pada konteks perusahaan di negara maju, misal negara-negara yang tergabung dalam Organisation for Economic Co-operation and Development (OECD). Pada penelitian Ambos et.al. (2008) terhadap institusi riset di UK menunjukkan bahwa tensi eksplorasi-eksploitasi mewujud dalam bentuk target akademis dan target komersialisasi riset. Pada level organisasi, tensi ini dapat dikelola dengan mendirikan transfer technology office. Sementara pada level individu, permasalah pengelolaan tensi menjadi lebih akut dalam diri individu periset. Peneliti lainnya, Hacket (2001) dan Phan dan Siegel (2006) menyebutkan bahwa agenda komersialisasi untuk menghasilkan keuntungan finansial lebih, dicapai melalui pembentukan struktur baru dan mempropagandakan aktivitas kewirausahaan. Lebih lanjut, para cendikiawan meyakini bahwa perubahan ini akan membawa revolusi akademik, menjadikan perguruan tinggi lebih bernuansa kewirausahaan, dimana output komersial akan menjadi norma penting dibanding sebagai sebuah aktivitas pilihan (Etzkowitz et.al., 2002; Owen-Smith, 2003).

Tabel 2. Ringkasan Isu Theoretical, Empirical dan Practical pada Riset AO

\begin{tabular}{|c|c|c|}
\hline Isu & Permasalahan & Acuan \\
\hline \multicolumn{3}{|l|}{ Theoretical Gap } \\
\hline \multirow{2}{*}{ Definisi dan konotasi } & $\begin{array}{l}\text { Ambiguitas definisi dan implikasi } \\
\text { eksplorasi dan eksploitasi }\end{array}$ & Gupta, Smith, \& Shalley (2006) \\
\hline & Kejelasan definisi & $\begin{array}{l}\text { Nosella, Cantarello, \& Filippi (2012); } \\
\text { Birkinshaw \& Gupta (2013) }\end{array}$ \\
\hline Asumsi mendasar & Kontinuitas versus ortogonalitas & $\begin{array}{l}\text { Gupta, Smith, Shalley (2006); Simsek } \\
\text { (2009) }\end{array}$ \\
\hline \multicolumn{3}{|l|}{ Empirical Gap } \\
\hline Disain riset & $\begin{array}{l}\text { disain riset berupa studi kasus atau } \\
\text { bukti anekdotal }\end{array}$ & $\begin{array}{l}\text { Markides \& Gharitou (2004); } \\
\text { Tushman \& O'Reilly (1996) }\end{array}$ \\
\hline Pengukuran & Perbedaan domain spesifik & Lavie, Stettner, \& Tushman (2010) \\
\hline \multicolumn{3}{|l|}{ Practical Gap } \\
\hline $\begin{array}{l}\text { Intensitas pengaruh } \\
\text { pada berbagai level }\end{array}$ & $\begin{array}{l}\text { Tensi lebih akut terjadi pada level } \\
\text { individu }\end{array}$ & Ambos et.al. (2008) \\
\hline
\end{tabular}

Sumber: dikembangkan untuk artikel ini

Meski terdapat isu teoritikal, empirikal maupun praktikal pada riset ambideksteritas organisasional, Junni et.al. (2013) menyimpulkan bahwa bukti empiris yang direview dalam studi meta analitisnya telah menghasilkan beberapa aspek yang bersifat impresif. Pertama, disamping beberapa perbedaan pengukuran, variabel outcome, level analisis dan sampel yang berasal dari berbagai industri, hasil penelitian yang menghubungkan ambideksteritas dengan kinerja dapat dikatakan robust. Kedua, meskipun beberapa studi di awal munculnya topik ini menggunakan disain riset studi kasus atau bukti anekdotal (e.g., Markides \& Gharitou, 2004; Tushman \& O'Reilly, 1996), namun banyak dari studi yang dilakukan beberapa tahun terakhir telah menggunakan data longitudinal sehingga mampu mendokumentasikan pengaruh ambideksteritas dari waktu ke waktu (e.g., Geerts, Blindenhach-Driessen, \& Gemmel, 2010; Goosen \& colleagues, 2012; GaspinWagner et al., 2012; Uotila \& colleagues, 2008). 
Selainitu,risetambideksteritasmengalami pertumbuhan pesat selama tahun 2005-2009 dengan fokus untuk menganalisis variabel anteseden, variabel pemoderasi dan pemediasi (e.g., Gupta, Smith, \& Shalley, 2006; Im \& Rai, 2008; Raisch \& Birkinshaw, 2008) serta variabel konsekwensi (Junni et.al., 2013). Konsep ini dipergunakan untuk menjelaskan berbagai fenomena (seperti: aliansi, model bisnis, unit venture) pada berbagai level analisis (individu, tim, partnership). Keluasan fenomena yang dapat dijelaskan oleh konsep ambideksteritas ini menjadikannya pedang bermata dua. Birkinshaw dan Gupta (2013) mengingatkan bahwa sebagai sebuah konsep jangkar, literatur ambideksteritas telah mencapai satu titik yang membutuhkan refocusing dan rethinking untuk memastikan bahwa popularitasnya tidak mengarah pada kegagalan. Riset ini berupaya memberi kontribusi dengan mengintegrasikan teori terdahulu dari para cendikia ambideksteritas struktural dan kontekstual.

Menariknya, beberapa cendikia memberi peringatan bahwa ambideksteritas organisasional bukanlah pilihan bagi semua organisasi karena dibutuhkan biaya yang besar dan tingkat kesulitan yang tinggi untuk mencapai (Duncan, 1976; Lubatkin et.al. 2006; March, 1991; Raisch et.al. 2009), melibatkan perbedaan model pembelajaran organisasi (e.g., Benner \& Tushman, 2003; Eisenhardt \& Martin, 2000), membutuhkan arsitektur dan proses organisasi yang berbeda dan inkonsisten (Smith \& Tushman, 2005), membutuhkan perubahan mindset (Gibson \& Birkinshaw, 2004; Smith \& Tushman, 2005) serta dapat menjadi jebakan kompetensi (Levinthal \& March, 1993). Bahkan ambideksteritas organisasional seringkali dianggap layak hanya untuk perusahaan besar karena kedua aktivitas ini membutuhkan sumber daya organisasi yang langka dan saling berkompetisi (March, 1991).

Para cendikia menjawab peringatan tersebut dengan mengelaborasikan literatur ambideksteritas organisasional dengan teori dan konteks tertentu, antara lain: absorptive capacity (Jansen, Van den Bosch, \& Volberda, 2005; Rothaermel \& Alexandre, 2009), teori pembelajaran organisasi (Holmqvist, 2004; Kang \& Snell, 2009; Mc Grath, 2001), teori paradoks (Andriopoulus \& Lewis, 2009, 2010; Papachroni, Heracleous, \& Paroutis, 2015), kapabilitas dinamis (O'Reilly \& Tushman, 2008; Taylor \& Helfat, 2009) dan konteks inter-organisasional (Gupta, Smith, \& Shalley, 2006; Lavie \& Rosenkopf, 2006; Lin, Yang, \& Demirkan, 2007; Riccaboni, \& Moliterni, 2009).

\section{IDENTIFIKASI ANTESEDEN}

Pada perkembangannya, riset ambideksteritas telah mengidentifikasi berbagai variabel anteseden, mediator, moderator, dan konsekwensi. Pada analisis anteseden, riset dikelompokkan menjadi dua yaitu anteseden yang dipengaruhi oleh faktor internal (organizational antecedents) dan faktor eksternal (environmental antecedent) dimana keduanya melibatkan berbagai level analisis dalam organisasi. Berdasar telaah literatur yang dipublikasikan di tahun 19902014 dari beberapa jurnal terkemuka di bidang managemen dan perilaku organisasi dapat diidentifikasi variabel-variabel anteseden dari aktivitas eksplorasi dan eksploitasi sebagaimana tersaji pada Tabel 1.3. Secara prinsip, Simsek (2009) berpendapat bahwa model ambideksteritas organisasional harus mengakomodir faktor-faktor yang berasal dari level intra-organisasi, inter-organisasi maupun lingkungan.

Tabel 3. Anteseden Aktivitas Eksplorasi dan Eksploitasi

\begin{tabular}{cll}
\hline No. & \multicolumn{1}{c}{ Variabel Anteseden } & \multicolumn{1}{c}{ Level individu/ tim } \\
\hline \multicolumn{1}{c}{ Acuan } \\
1. & Dedicated ambidextrous competencies & Hafkesbrink, Bachem, \& Kulenovic (2012) \\
2. & $\begin{array}{l}\text { Proses kognitif } \\
\text { Perilaku individu dalam top management } \\
\text { 3. }\end{array}$ & Smith \& Tushman 2005 \\
4. & Karakteristik idiosinratik & Lubatkin et.al. (2006) \\
\hline
\end{tabular}




\begin{tabular}{|c|c|c|}
\hline No. & Variabel Anteseden & Acuan \\
\hline \multicolumn{3}{|c|}{ Level tim } \\
\hline 1. & Internal proses dalam TMT & Tushman \& O’Reilly (1997) \\
\hline 2. & Mekanisme integrasi & Smith \& Tushman (2005) \\
\hline 3. & Komposisi tim pendiri & Beckman (2006) \\
\hline 4. & Komposisi tim & Peretti \& Negro (2006) \\
\hline \multirow[t]{2}{*}{5.} & Perilaku integrasi & Lubatkin et.al. (2006) \\
\hline & Level Intra-organisasi & \\
\hline \multirow[t]{2}{*}{1.} & Slack resources & Voss, Sirdekmush \& Voss (2008) \\
\hline & Konteks pendukung: & \\
\hline 2. & System, process, belief & Ghosal \& Bartlett (1994) \\
\hline 3. & Meta routine dan job enrichment & Adlet et.al. (1999) \\
\hline 4. & Leader with complex behavior & Denison et.al. (1995); Lewis (2000) \\
\hline 5. & Shared vision & Bartlett \& Gibson (1989) \\
\hline 6. & $\begin{array}{l}\text { Combination of stretch, discipline, support } \\
\text { and trust }\end{array}$ & Gupta \& Birkinshaw (2004) \\
\hline \multirow[t]{2}{*}{7.} & $\begin{array}{l}\text { Konteks sosial: Status recognition, visibility, } \\
\text { responsibility }\end{array}$ & Taylor \& Helfat (2009) \\
\hline & Level Inter-organisasi & \\
\hline 1. & Sentralitas dan diversitas jaringan & Simsek (2009) \\
\hline 2. & Long-term interorganizational relationship & Im \& Rai (2008) \\
\hline 3. & Alliance formation & Lavie \& Rosenkopf (2006) \\
\hline 4. & Network ambidexterity & Kauppila (2010) \\
\hline \multirow[t]{2}{*}{5.} & Externalizing & Holmqvist (2004); \\
\hline & Lingkungan & \\
\hline 1. & $\begin{array}{l}\text { Dinamisme lingkungan bisnis dan tingkat } \\
\text { persaingan }\end{array}$ & $\begin{array}{l}\text { Auh \& Menguc (2005); Floyd \& Lane (2000) } \\
\text { Levinthal \& March (1993), March (1991); } \\
\text { Volberda (1998) }\end{array}$ \\
\hline 2. & Environmental munificence & Zahra (1993) \\
\hline
\end{tabular}

Sumber: dikembangkan untuk artikel ini

Sebagian besar riset ambideksteritas organisasional hanya fokus membahas struktur atau konteks organisasi yang mendukung tercapainya ambideksteritas (e.g., Gibson \& Birkinshaw, 2004; He \& Wong, 2004; Lubatkin et.al., 2006), akan tetapi bagaimana cara mencapai ambideksteritas dan pada kondisi yang bagaimanakah dapat dicapai kesuksesan, belum banyak terjelaskan. Penulis berargumen bahwa dimensi struktur dan konteks organisasional akan menciptakan fondasi mikro dimana interaksi keduanya akan menghasilkan outcome organisasional berupa proses eksploitatif dan eksploratif (Simsek, 2009). Lebih lanjut, pemahaman mendalam atas anteseden ambideksteritas organisasional sebagaimana diidentifikasi oleh tabel di atas, akan membantu mencapai tujuan kedua riset ini dengan cara mengungkap mekanisme pencapaian ambideksteritas pada level individu yang memampukan terciptanya ambideksteritas pada level organisasi dengan cara mengeksplorasi elemen struktur berupa organizational capital dan elemen perilaku berupa social capital dan human capital menggunakan kerangka Kang dan Snell (2009).

Memperkuat hal tersebut di atas, faktor internal organisasi seperti perilaku kolektif individu juga perlu diakomodasi untuk melihat pengaruhnya terhadap aktivitas eksplorasi dan eksploitasi. Perilaku keseharian individu tampaknya berakar dari kepribadian individu (Hofmann \& Jones, 2005). Schudy (2010) menduga bahwa kepribadian individu akan membentuk perilaku ambidektrus. Penelitian sebelumnya telah menganalisa ide dari perilaku keseharian ini sebagai 
salah satu anteseden dari ambideksteritas, misalnya Adler, Goldoftas, \& Levine (1999) yang mengatakan bahwa meta-rutinitas bentuk kolektif dari perilaku keseharian - berkontribusi pada kemampuan untuk menyeimbangkan eksplorasi dan eksploitasi. Güttel dan Konlechner (2009) menyebutkan norma spesifik dan pola perilaku kolektif sebagai bentuk karakteristik idiosinratik mendukung terbentuknya ambideksteritas. Rutinitas dan norma tersebut timbul dari perilaku keseharian individu, disebut sebagai kepribadian, yang termanifestasi ke dalam level kolektif, disebut sebagai kepribadian kolektif (Hofmann \& Jones, 2005).

Terdapat tiga aliran besar riset ambideksteritas organisasional dalam memandang mekanisme pencapaian ambideksteritas organisasional, yaitu: ambideksteritas struktural, ambideksteritas kontekstual dan ambideksteritas berdasar kepemimpinan. Para cendikia ambideksteritas struktural berpendapat bahwa struktur organisasi bagi aktivitas eksplorasi dan eksploitasi harus dipisahkan dimana unit eksplorasi biasanya lebih kecil, lebih terdesentralisasi dan lebih fleksibel dibanding unit eksploitasi (Benner \& Tushman, 2003). Pemisahan struktur ini berdasar asumsi bahwa mindset dan rutinitas organisasional yang dibutuhkan untuk eksplorasi sangat berbeda dengan yang dibutuhkan untuk eksploitasi, dan menyatukan keduanya bukanlah hal yang mungkin (Gupta, Smith, \& Shalley, 2006). Dikotomi dalam struktur ini, merupakan lanjutan dari pemikiran Burns dan Stalker (1961), Christensen dan Bower (1996), Christensen (1997), dan Duncan (1976). Adapun solusi pemisahan tersebut didasarkan pada dua prinsip yaitu pemisahan secara spasial pada unit bisnis atau level korporat untuk memastikan bahwa setiap unit dapat merespon tuntutan lingkungannya secara spesifik (Duncan, 1976; Benner \& Tushman, 2003; Lawrence \& Lorsch, 1967; Tushman \& O'Reilly, 1996) atau dengan membentuk struktur paralel dimana struktur ini memungkinkan individu di dalamnya untuk berganti peran eksplorasi atau eksploitasi sesuai tugas yang sedang dijalankan (McDonough \& Leifer, 1983). Riset ambideksteritas struktural ini fokus pada peran kritis dari managemen puncak dan posisi mereka sebagai pihak yang melaksanakan fungsi intermediasi (Gilbert, 2006) dan fungsi integrasi (O'Reilly \& Tushman, 2008, Smith \& Tushman, 2005).

Sebaliknya, ambideksteritas kontekstual mensyaratkan collective sense-making, a common mindset, dan mutual absorptive capacity di antara individu yang memiliki perbedaan latar belakang pengetahuan agar mereka dapat menjalankan peran eksplorasi maupun eksploitasi secara temporal. Sebagai contoh Adler, Goldoftas, \& Levine (1999) mendiskripsikan bagaimana seorang karyawan melakukan pergantian tugas harian yang sangat berbeda - efisiensi (eksploitasi) dan inovasi (eksplorasi) - di sebuah perusahaan manufaktur otomotif. Memperkuat hal ini, Gibson dan Birkinshaw (2004) dengan merujuk pada Ghosal dan Bartlett (1994), mendiskripsikan hal ini sebagai ambideksteritas kontekstual yaitu ambideksteritas yang berasal dari konteks organisasi berupa proses atau sistem yang memampukan dan mendorong individu supaya mampumembagiwaktunya diantara tugas yang bertentangan agar dapat mencapai keselarasan dan adaptasi. Adapun riset ambideksteritas berdasar kepemimpinan dilakukan oleh Floyd dan Lane (2000), Beckman (2006), Jansen et.al. (2008) dan Lubatkin et.al. (2006) yang menginvestigasi secara ekstensif karakteristik dan proses kepemimpinan yang memampukan managemen puncak agar dapat melakukan aktivitas eksplorasi dan eksploitasi secara simultan. Keputusan melakukan eksplorasi dan eksploitasi secara simultan ini menjadi tanggung jawab managemen puncak melalui mekanisme integrasi (Smith \& Tushman, 2005).

Teori kapabilitas dinamis (Eisenhardt \& Martin, 2000; Helfat et.al., 2007; Teece et.al., 1997; Teece, 2006) berperan sebagai pijakan awal dan dasar pemikiran, kemudian berlanjut pada teori pembelajaran organisasi (e.g., March, 1991) sebagai dasar memahami eksplorasi dan eksploitasi. Perspektif teori lain yang juga ada dalam riset ini adalah teori ambideksteritas organisasional (Benner \& Tushman, 2003; Gibson \& Birkinshaw, 2004) untuk melihat manfaat dari dilakukannya aktivitas eksplorasi dan eksploitasi dalam organisasi serta teori modal sosial (e.g., 
Nahapiet \& Ghoshal, 1998; Rogan \& Mors, 2014) sebagai dasar untuk melihat struktur jaringan sosial.

Teori kapabilitas dinamis menekankan pada peran kepemimpinan strategik yang secara sesuai melakukan adaptasi, integrasi dan rekonfigurasi ketrampilan dan sumber daya dalam organisasi dengan tujuan menyesuaikan diri dengan perubahan lingkungan (Eisenhardt \& Martin, 2000; Helfat et.al., 2007; Teece et.al., 1997; Teece, 2006). Kemampuan organisasi dalam memanfaatkan peluang melalui orkestrasi dan integrasi sumber daya yang dimiliki dan sumber daya baru untuk mengatasi ketergantungan menjadi inti dari kapabilitas dinamis. Kapabilitas tersebut mewujud dalam bentuk rutinitas atau sistem (Winter, 2003; Zott, 2003), atau rutinitas untuk mempelajari rutinitas-rutinitas baru (Eisenhardt \& Martin, 2000) dan dipandang sebagai sumber keunggulan kompetitif jangka panjang.

Sayangnya banyak riset yang mengeksplorasi bagaimana kapabilitas dinamis memungkinkan perusahaan untuk beradaptasi pada perubahan pasar dan tehnologi masih sangat awal dan bersifat konseptual (O'Reilly \& Tushman, 2007). Jenis rutinitas dan kompetensi apa yang dapat dihubungkan dengan kompetisi efektif jangka pendek pada pasar dan tehnologi yang telah matang, dan kompetisi jangka panjang melalui adaptasi pada pasar dan tehnologi baru belum terjelaskan. Hal penting lain yang belum terjelaskan adalah kapabilitas spesifik apa yang dapat memfasilitasi eksplorasi dan eksploitasi (March, 1991).

Dengan mengacu pada keterkaitan ketiga faktor yaitu terjadinya trade-off, mekanisme ambideksteritas pada level individu dan peran modal sosial pada aktivitas eksplorasi dan eksploitasi, maka riset ini bermaksud mendalami bagaimana hubungan ketiga faktor tersebut pada aktivitas eksplorasi dan eksploitasi di perguruan tinggi sekaligus menjawab tantangan riset Simsek (2009). Riset ini juga mencoba memberikan bukti bahwa ketiga faktor tersebut pada eksploitasi dan eksplorasi pada level individu serta implikasinya terhadap pembentukan kemampuan ambideksteritas dalam organisasi khususnya perguruan tinggi.
Beberapa argumen pemilihan perguruan tinggi sebagai konteks dalam penelitian ini. Pertama, adanya harapan bahwa perguruan tinggi dapat berkontribusi langsung pada pertumbuhan ekonomi dan memberi perhatian khusus pada lingkungan industri lokal. Kedua, perubahan kebijakan pemerintah untuk lebih menggiatkan riset yang dapat menghasilkan hak kekayaaan intelektual, seperti: paten atau lisensi. Ketiga, tekanan yang besar dan tersedianya insentif bagi perguruan tinggi untuk melahirkan start-up company yang berbasis tehnologi atau menjalin kerjasama antara perguruan tinggi dan industri. Upayaupaya tersebut juga semakin meningkat seiring tuntutan bagi perguruan tinggi untuk beroperasi sebagaimana layaknya korporasi sehingga memunculkan konsep entreprenuerial universities (Phan \& Siegel, 2006) pada level organisasi dan istilah academic entrepereneur (Grimaldi et.al., 2011) pada level individu.

\section{KESIMPULAN}

Walau disadari pentingnya ambideksteritas pada level individu bagi pencapaian ambideksteritas pada level organisasi, namun studi pada level individu masih jarang dilakukan (Mom et.al., 2009; Raisch et.al., 2009). Kelangkaan ini dimungkinkan karena terdapat beberapa tantangan yang harus dijawab. Pertama, meskipun para cendikia mengakui bahwa proses adaptif yang mendorong kapabilitas organisasi untuk menjadi ambidekstrus berada pada level individu, namun mengamati proses ini secara empiris cukup sulit dilakukan. Jadi, banyak penelitian empiris menggunakan data pada level organisasi atau unit untuk membuat kesimpulan tentang perilaku pada level individu (e.g., Gibson \& Birkinshaw, 2004) atau secara kualitatif atau menggunakan data sampel yang kecil dengan generalisasi terbatas (e.g., Taylor \& Helfat, 2009; Tushman \& O’Reilly, 1996).

Tantangan kedua dalam hal teoretikal. Gupta et.al. (2006) mereview trade-off antara eksplorasi-eksploitasi, mereka membuat proposisi bahwa ko-eksistensi keduanya dalam sebuah domain seperti dalam diri individu bukanlah hal yang mungkin, dan hanya sebuah sistem yang memiliki karakteristik 
loosely coupled system seperti tim, unit bisnis atau perusahaan yang mungkin menjadi ambidekster. Hasilnya, beberapa studi perilaku ambidekterus dari manager terbatas pada proses kognitif untuk menyeimbangan eksplorasi dan eksploitasi (e.g., Smith \& Tushman 2005).

\section{DAFTAR PUSTAKA}

Anderson, N., \& Gasteiger, R. M. (2007). 24 Helping creativity and innovation thrive in organizations: functional and dysfunctional perspectives. Research companion to the dysfunctional workplace: Management challenges and symptoms, 422.

Auh, S., \& Menguc, B. (2005). Balancing exploration and exploitation: The moderating role of competitive intensity. Journal of Business Research, 58(12), 1652-1661.

Atuahene-Gima, K. (2005). Resolving the capability-rigidity paradox in new product innovation. Journal of Marketing, 69(4), 61-83.

Baum, J. A., Li, S. X., \& Usher, J. M. (2000). Making the next move: How experiential and vicarious learning shape the locations of chains' acquisitions. Administrative Science Quarterly, 45(4), 766-801.

Benner, M. J., \& Tushman, M. (2002). Process management and technological innovation: A longitudinal study of the photography and paint industries. Administrative Science Quarterly, 47(4), 676-707.

Bodwell, W., \& Chermack, T. J. (2010). Organizational ambidexterity: Integrating deliberate and emergent strategy with scenario planning. Technological Forecasting and Social Change, 77(2), 193-202.

Christensen, T. J. (1997). Perceptions and alliances in Europe, 1865-1940. International Organization, 51(01), 6597.
De Visser, M., de Weerd-Nederhof, P., Faems, D., Song, M., Van Looy, B., \& Visscher, K. (2010). Structural ambidexterity in NPD processes: A firm-level assessment of the impact of differentiated structures on innovation performance. Technovation, 30(5), 291-299.

Eisenhardt, K. M., \& Martin, J. A. (2000). Dynamic capabilities: what are they?. Strategic management journal, 21(1011), 1105-1121.

Fang, C., Lee, J., \& Schilling, M. A. (2010). Balancing exploration and exploitation through structural design: The isolation of subgroups and organizational learning. Organization Science, 21(3), 625-642.

Gibson, C. B., \& Birkinshaw, J. (2004). The antecedents, consequences, and mediating role of organizational ambidexterity. Academy of management Journal, 47(2), 209-226.

Grimaldi, R., Kenney, M., Siegel, D. S., \& Wright, M. (2011). 30 years after Bayh-Dole: Reassessing academic entrepreneurship. Research Policy, 40(8), 1045-1057.

Güttel, W. H., \& Konlechner, S. W. (2009). Continuously hanging by a thread: Managing contextually ambidextrous organizations. Schmalenbach Business Review, 61, 150-171.

Gupta, A. K., Smith, K. G., \& Shalley, C. E. (2006). The interplay between exploration and exploitation. Academy of management journal, 49(4), 693-706.

Han, M., \& Celly, N. (2008). Strategic ambidexterity and performance in international new ventures. Canadian Journal of Administrative Sciences/ Revue Canadienne des Sciences de l'Administration, 25(4), 335-349.

Hannan, M. T., \& Freeman, J. (1984). Structural inertia and organizational change. American sociological review, 
149-164.

He, Z. L., \& Wong, P. K. (2004). Exploration vs. exploitation: An empirical test of the ambidexterity hypothesis. Organization science, 15(4), 481-494.

House, C. H., \& Price, R. L. (2009). The HP Phenomenon.

Im, G., \& Rai, A. (2008). Knowledge sharing ambidexterity in long-term interorganizational relationships. Management Science, 54(7), 1281-1296.

Jansen, J. J., George, G., Van den Bosch, F. A., \& Volberda, H. W. (2008). Senior team attributes and organizational ambidexterity: The moderating role of transformational leadership. Journal of Management Studies, 45(5), 982-1007.

Kang, S. C., \& Snell, S. A. (2009). Intellectual capital architectures and ambidextrous learning: a framework for human resource management. Journal of Management Studies, 46(1), 65-92.

Kauppila, O. P. (2010). Creating ambidexterity by integrating and balancing structurally separate interorganizational partnerships. Strategic organization, 8(4), 283-312.

O Reilly, C. A., \& Tushman, M. L. (2004). The ambidextrous organization. Harvard business review, 82(4), 74-83.

Li, C. R., Lin, C. J., \& Chu, C. P. (2008). The nature of market orientation and the ambidexterity of innovations. Management Decision, 46(7), 10021026.

Li, Y., Vanhaverbeke, W., \& Schoenmakers, W. (2008). Exploration and exploitation in innovation: Reframing the interpretation. Creativity and innovation management, 17(2), 107-126.

Lin, Z., Yang, H., \& Demirkan, I. (2007). The performance consequences of ambidexterity in strategic alliance formations: Empirical investigation and computational theorizing. Management science, 53(10), 1645-1658.

Louçã, F., \& Mendonça, S. (2002). Steady change: the 200 largest US manufacturing firms throughout the 20th century. Industrial and Corporate Change, 11(4), 817-845.

Lubatkin, M. H., Simsek, Z., Ling, Y., \& Veiga, J. F. (2006). Ambidexterity and performance in small-to medium-sized firms: The pivotal role of top management team behavioral integration. Journal of management, 32(5), 646-672.

March, J. G. (1991). Exploration and exploitation in organizational learning. Organization science, 2(1), 71-87.

Mom, T. J., Van Den Bosch, F. A., \& Volberda, H. W. (2009). Understanding variation in managers' ambidexterity: Investigating direct and interaction effects of formal structural and personal coordination mechanisms. Organization Science, 20(4), 812-828.

Markman, G. D., Siegel, D. S., \& Wright, M. (2008). Research and technology commercialization. Journal of Management Studies, 45(8), 1401-1423.

Nelson, R. R., \& Winter, S. G. (1982). The Schumpeterian tradeoff revisited. The American Economic Review, 72(1), 114132.

Nemanich, L. A., \& Vera, D. (2009). Transformational leadership and ambidexterity in the context of an acquisition. The Leadership Quarterly, 20(1), 19-33.

O Reilly, C. A., \& Tushman, M. L. (2004). The ambidextrous organization. Harvard business review, 82(4), 74-83.

O’Reilly, C. A., \& Tushman, M. L. (2008). Ambidexterity as a dynamic capability: Resolving the innovator's dilemma. Research in organizational behavior, 28, 185-206.

Stubbart, C. I., \& Knight, M. B. (2006). The case of the disappearing firms: empirical 
evidence and implications. Journal of Organizational Behavior, 27(1), 79-100.

Raisch, S., Birkinshaw, J., Probst, G., \& Tushman, M. L. (2009). Organizational ambidexterity: Balancing exploitation and exploration for sustained performance. Organization Science, 20(4), 685-695.

Rogan, M., \& Mors, M. L. (2014). A network perspective on individuallevel ambidexterity in organizations. Organization Science, 25(6), 18601877.

Rothaermel, F. T., \& Deeds, D. L. (2004). Exploration and exploitation alliances in biotechnology: a system of new product development. Strategic management journal, 25(3), 201-221.

Rothaermel, F. T., \& Alexandre, M. T. (2009). Ambidexterity in technology sourcing: The moderating role of absorptive capacity. Organization science, 20(4), 759-780.

Smith, W. K., \& Tushman, M. L. (2005). Managing strategic contradictions: A top management model for managing innovation streams. Organization science, 16(5), 522-536.

Staw, B. M., Sandelands, L. E., \& Dutton, J. E. (1981). Threat rigidity effects in organizational behavior: A multilevel analysis. Administrative science quarterly, 501-524.

Teece, D. J. (1982). Towards an economic theory of the multiproduct firm. Journal of Economic Behavior \& Organization, 3(1), 39-63.

Tushman, M. L., Virany, B., \& Romanelli, E. (1985). Executive succession, strategic reorientations, and organization evolution: The minicomputer industry as a case in point. Technology in Society, 7(2-3), 297-313.

Tushman, M. L., \& O'Reilly III, C. A. (1996). Managing evolutionary and revolutionary change. California Management Review, 38(4), 8-28.

Tushman, M. L., Charles O’Reilly, Harreld, B. (2013). Leading Strategic Renewal: Proactive Punctuated Change through Innovation Streams and Disciplined Learning.

Venkatraman, N., Lee, C. H., \& Iyer, B. (2007). Strategic ambidexterity and sales growth: A longitudinal test in the software sector. In Unpublished Manuscript (earlier version presented at the Academy of Management Meetings, 2005).

Voelpel, S. C., Leibold, M., \& Tekie, E. B. (2006). Managing purposeful organizational misfit: Exploring the nature of industry and organizational misfit to enable strategic change. Journal of Change Management, 6(3), 257-276.

Volberda, H. W., \& Lewin, A. Y. (2003). Co-evolutionary dynamics within and between firms: From evolution to coevolution. Journal of management studies, 40(8), 2111-2136.

Winter, S. G. (2003). Understanding dynamic capabilities. Strategic management journal, 24(10), 991-995.

Wernerfelt, B. (1984). A resource-based view of the firm. Strategic management journal, 5(2), 171-180.

Zott, C. (2003). Dynamic capabilities and the emergence of intraindustry differential firm performance: insights from a simulation study. Strategic management journal, 24(2), 97-125. 